\title{
Role of the multidisciplinary team in the care of the tracheostomy patient
}

\section{Barbara Bonvento' \\ Sarah Wallace ${ }^{1,2}$ \\ James Lynch' \\ Barry Coe' \\ Brendan A McGrath'}

'Acute Intensive Care Unit, University Hospital South Manchester,

Manchester, ${ }^{2}$ Royal College of Speech and Language Therapists, London, UK

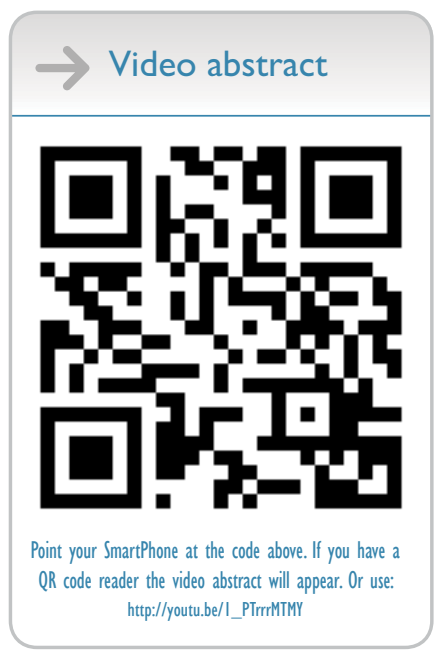

Correspondence: Brendan A McGrath Acute Intensive Care Unit, University Hospital South Manchester, Southmoor Road, Wythenshawe, Manchester M23 9LT, UK

Tel +44 I6I $29 \mid 6420$

Fax +44 I6I 29| 642।

Email brendan.mcgrath@manchester. ac.uk
This article was published in the following Dove Press journal:

Journal of Multidisciplinary Healthcare

II October 2017

Number of times this article has been viewed

\begin{abstract}
Tracheostomies are used to provide artificial airways for increasingly complex patients for a variety of indications. Patients and their families are dependent on knowledgeable multidisciplinary staff, including medical, nursing, respiratory physiotherapy and speech and language therapy staff, dieticians and psychologists, from a wide range of specialty backgrounds. There is increasing evidence that coordinated tracheostomy multidisciplinary teams can influence the safety and quality of care for patients and their families. This article reviews the roles of these team members and highlights the potential for improvements in care.
\end{abstract}

Keywords: tracheotomy, physiotherapist, Speech \& Language, Nursing

\section{Introduction}

Tracheostomy is one of the first recorded surgical procedures and refers to an artificial communication between the trachea and the anterior neck. It can be confused with laryngectomy, which refers to complete excision of the larynx, usually as treatment for laryngeal cancer, with the trachea terminating on the anterior neck. Patients with a laryngectomy therefore have no connection from their upper airways (nose and mouth) to their lungs. Whilst tracheostomies were classically performed by surgeons to relieve airway obstruction, the majority of tracheostomies are now performed in critically ill patients in order to facilitate weaning from prolonged mechanical ventilatory support. Other indications include offering a degree of protection against pulmonary aspiration, to aid clearance of respiratory secretions and to facilitate long-term invasive ventilation.

Between 5,000 and 6,000 surgical tracheostomies are performed annually in adults in the UK. ${ }^{1}$ Although some surgical tracheostomies are performed for emergency airway obstruction, the majority of surgical procedures are elective, associated with extensive head and neck surgery and inserted to maintain perioperative airway patency. Approximately 12,000-14,000 (almost exclusively) percutaneous tracheostomies are performed in the UK's intensive care units (ICUs) annually.,3 The main indication for tracheostomy in ICU is to facilitate weaning from prolonged mechanical ventilation. Tracheostomies are well tolerated and allow patients to be managed without sedation whilst still receiving invasive mechanical ventilatory support. This has clear advantages over prolonged endotracheal intubation, although the best timing for tracheostomy in different patient populations remains unclear. ${ }^{4}$ Data from across Europe tell us that $7 \%-16 \%$ of critical care admissions will be managed with a tracheostomy at some point in their care, ${ }^{5-7}$ with
Dobmit your manuscript | www.dovepress.com 
similar proportions in the USA contributing to their 100,000 or so annual tracheostomy procedures..$^{8-10}$

The landscape has therefore evolved such that around two-thirds of hospital inpatients with tracheostomy are primarily managed by nonsurgical teams, usually from intensive care medicine or respiratory backgrounds. ${ }^{3,11}$ This evolution has coincided with developments in the delivery of health care in general whereby the increasingly complex needs of patients and their families call for multidisciplinary teams (MDTs) to achieve optimal patient outcomes. ${ }^{12,13}$ Fortunately, the roles of medical, nursing and allied health staff in safely managing and rehabilitating all patients with tracheostomies have also advanced significantly, both individually and collaboratively. It is worth noting that multidisciplinary care of the ventilated ICU patients has also evolved such that patients are increasingly offered opportunities to wean from mechanical ventilation with tracheostomy often delayed to facilitate trials of extubation. ${ }^{3}$

Tracheostomy care can be one of the best examples of multidisciplinary care, with many different medical, nursing and allied health teams being required to deliver coordinated and effective care. There have been calls in the literature for better coordinated management of tracheostomy patients since the early 1990s, followed by published examples and accounts of successful MDTs. ${ }^{14-21}$ These teams typically included speech and language therapists (SLTs), physiotherapists and nurse specialists, with early teams usually led by medical staff from head and neck surgical, neurology, pulmonology or critical care backgrounds. The role of such teams typically included the following:

- Setting, reviewing and monitoring a weaning regime (from mechanical ventilation) including decannulation

- Setting goals for cuff deflation, use of speaking valve and capping off the tubes

- Identifying patients for tracheostomy tube changes; either routine changes or downsizing/changing the type of tracheostomy tube in line with the weaning process

- Identifying patients who need further investigation by other specialties

- Providing education

- Monitoring and auditing tracheostomy care

- Maintaining a safe environment with appropriate emergency equipment for this vulnerable patient group

This article reviews the roles of the MDT in the care of the tracheostomy patients and outlines the potential benefits of a coordinated multidisciplinary approach for the patients, their family and our health care systems.

\section{What is the problem with tracheostomies?}

In adult practice, the requirement for tracheostomy usually indicates important underlying pathology that can have a significant impact on morbidity and mortality. A review of more than 23,000 North American inpatient records where a tracheostomy was performed demonstrated that only $80 \%$ survived to hospital discharge, with as few as $60 \%$ surviving if there were significant comorbidities. ${ }^{22}$ Similar figures exist for the UK and Europe. ${ }^{3,11}$

Whilst tracheostomies are increasingly commonplace, patient safety incidents associated directly with their use are unfortunately also increasing. A number of high-profile reports from registries of reported patient safety incidents have helped to identify key themes around failings with tracheostomy care. ${ }^{23-26}$ Such themes include inadequacies in staff education, equipment provision, monitoring and the response to clinical incidents. When a clinical incident occurs relating to a tracheostomy, the chance of some harm occurring is between $60 \%$ and $70 \%$, depending on location. ${ }^{27,28}$

The UK National Confidential Enquiry into Patient Outcome and Death (NCEPOD) conducted a national study into tracheotomy care, the lessons of which are applicable to multidisciplinary health care professionals working with tracheostomy patients. The report identified variability in the composition and performance of tracheostomy MDTs, noting that multidisciplinary care was fragmented, with long delays in referrals to SLTs and other allied health professional (AHP) groups. ${ }^{3}$ The report made a number of significant recommendations aimed at increasing the safety and quality of care, recognizing the key role that that the MDT can play. Better coordination and collaboration between specialties and professions could significantly increase the accessibility of relevant expertise for tracheostomy patients and significantly affect the quality of care delivered to this vulnerable group. ${ }^{29}$

The goal of tracheostomy care is to provide a safe environment for management of the patients, whether they are adults or children or cared for in hospitals or our communities. Each member of the MDT has unique skills around tracheostomy care that he/she can bring to the bedside. AHPs can provide specialist skills and expertise in assessment and treatment of swallowing and communication needs, tracheostomy tube choice, decannulation decisions, nutrition, psychological well-being and maintenance of a patent airway. ${ }^{30}$ Specialist multidisciplinary staff help to provide the consistency and continuity that is associated with improvements in care. ${ }^{31}$ The principle roles of different health care professionals are outlined in the following section. 


\section{Roles of the multidisciplinary tracheostomy team Respiratory (physio)therapists}

Although the role can vary with institution or country, respiratory physiotherapists are independent practitioners with skills in assessment and treatment of respiratory problems, including the management of those dependent on mechanical ventilatory support. ${ }^{32}$ Chest clearance has always been a core function of physiotherapists. The first description of chest clearance exercises appeared as early as 1915 and remains a key part of the management of tracheostomy patients whose ability to humidify, cough and swallow chest secretions may be significantly impaired or absent. ${ }^{33}$

Active cycle of breathing techniques (ACBTs) is a relatively basic form of chest clearance employed to aid sputum expectoration. It is accessible to most physiotherapists and applicable to a wide variety of patient groups. ${ }^{34}$ This technique combines a cycle of relaxed breaths with thoracic expansions and breath hold, followed by forced expiration. This technique is effective and safe in spontaneously breathing patients and also easily applied to those with a tracheostomy. ${ }^{35}$

In tracheotomized patients, chest clearance can also be aided with the use of manual hyperinflation, administering passive positive pressure breaths by inflating the lungs of the patients, holding and then releasing the applied pressure. In addition to clearance of sputum, dependent areas of pulmonary collapse can be re-recruited with consequent improved lung compliance and gas exchange. ${ }^{36}$ An extension of this mechanism is to apply a negative pressure in expiration, thus mimicking a cough effort. This change in pressure helps to replicate a cough effort, aiding sputum clearance. ${ }^{37}$ This insufflation/exsufflation device, commonly referred to as a "cough assist", can be used with a facemask but also on tracheotomized patients, using an adaptor attached to the tracheostomy tube.

Intermittent positive pressure breathing (IPPB) devices can assist the physiotherapist by timing a mechanical pressure-supported inspiration with the patient's own respiratory effort. IPPB can improve lung volumes and decrease the work of breathing, especially in the postsurgical setting. The American Association for Respiratory Care (AARC) recommends the use only for patients with atelectasis and suggests the effects of IPPB are short term; ${ }^{38}$ however, IPPB is still widely used elsewhere. As with the cough assist devices, IPPB can be used through a facemask or used attached to a tracheostomy tube.
Physiotherapists may consider the use of pharmacological therapies in mobilizing secretions to aid expectoration. Therapies include simple nebulized drugs such as isotonic $0.9 \%$ saline solution through to higher concentration hypertonic $9 \%$ saline, or mucolytics. A simple spirometer can be used to monitor the effects on the airways. ${ }^{35}$

Suctioning secretions through artificial airway devices can remove or retrieve pulmonary secretions from the proximal airways. Suctioning can provoke transient hypoxemia and cardiac arrhythmias, especially in the critically ill, and experienced practitioner will know how frequently to perform suction on a given patient. However, there are no absolute contraindications, as problems are usually short-lived and related to the baseline stability of the patient. ${ }^{37}$

Physiotherapists also have a key role to play in reducing the incidence and impact of ventilator-associated pneumonia (VAP), which affects between $9 \%$ and $27 \%$ of all ventilated patients with associated mortality estimates between 33\% and $50 \%{ }^{39}$ Chest physiotherapy treatments in conjunction with diagnostic interventions such as nondirected bronchoalveolar lavage have been shown to reduce the incidence of VAP. ${ }^{40}$

The role of the typical respiratory physiotherapist in Europe also includes managing of the physical rehabilitation of the patients. This may be especially pertinent in ICU where the consequences of mechanical ventilation, with prolonged bed rest or inactivity, muscle wasting, weakness and general deconditioning, are more marked. ${ }^{41}$ The UK National Institute for Health and Clinical Excellence (NICE) guidelines have emphasized the importance of this aspect of treatment..$^{42}$ Early mobilization is an effective and safe strategy in this situation, often overseen by physiotherapists once cardiorespiratory stability has been achieved..$^{43}$ Not only this can improve functional mobility outcomes, but also it is beneficial for cognitive and respiratory well-being. Mobilization can be safely achieved whilst the patient is still attached to a ventilator. Various scoring systems have been described that track progress and function, and may predict future functionality and hospital discharge destination. ${ }^{44,45}$ Whilst some are applicable only in the critically ill, universally adopted systems to describe progress promote the same dialog between health care professionals and can facilitate effective handover between care locations..$^{46,47}$

Assessing the suitability of a particular patient for decannulation can be complex, and the role of the physiotherapist here is vital. Simple measures such as peak expiratory or cough flow alone are not reliable predictors of decannulation success. The need for ventilatory support, oral and pulmonary 
secretion management, swallowing adequacy, airway patency and the course of underlying medical conditions are notoriously difficult to predict and will require the input of the $\mathrm{MDT}^{48}$ Whilst various scoring systems have been proposed and various decannulation strategies described, there is no consensus on best practice. ${ }^{49}$

\section{Speech and language therapists (pathologists)}

Assessment, diagnosis and management of communication and swallowing difficulties are key parts of the SLT role in the care of tracheostomy patients. However, expertise is not confined to this area alone, and a series of national reports have highlighted the potential for SLT services to further enhance the care of tracheostomy patients. , $^{3,50,51}$

Communication difficulties can be expected and predicted in between $16 \%$ and $24 \%$ patients requiring tracheostomies and laryngectomies, especially those who require prolonged mechanical ventilation. ${ }^{52}$ Careful selection and use of tracheostomy tubes, fenestrations, cuff management and novel communication techniques can have a significant effect on speech facilitation and a positive impact on patient anxiety levels. ${ }^{52,53}$ An inflated tracheostomy tube cuff excludes the larynx and upper airway from normal airflow patterns, and one of the best methods of facilitating communication is to deflate the cuff as soon as possible. ${ }^{19}$ Cuff deflation can add a significant work of breathing to the patient however, especially if upper airway gas flow is augmented by the use of one-way speaking valves. ${ }^{54,55}$ The potential impact of therapies has a clear overlap with historical roles of the multidisciplinary care team, but specialist SLTs are well placed to understand these interactions. Early identification of suitable patients for cuff deflation and facilitating vocalization may have additional positive effects in promoting laryngeal function and resensitization of laryngopharyngeal mucosa and reflexes. ${ }^{56} \mathrm{~A}$ team approach can result in the earlier introduction of speaking valves and substantial increase in their use. ${ }^{19,57}$ SLT evaluation of voice quality can also assist in the detection of dysphonia and vocal fold immobility, for example, as a result of intubation trauma or cardiothoracic surgery and facilitate involvement of ENT opinion as needed. Early identification of vocal fold palsy is important given the associated increased risk of aspiration in dysphagia patients. ${ }^{58}$ Differential diagnosis and treatment of communication difficulties associated with specific tracheostomized patient groups, such as those with neurogenic or head and neck cancer etiology, also requires specialist SLT intervention. ${ }^{51,59}$
Assessment and management of oropharyngeal secretions can promote successful cuff deflation and may be predictive of the ability to tolerate oral intake or play a role in reducing respiratory infections. ${ }^{30,60}$ Oral secretion management may be helped by tracheostomy tubes with subglottic suction ports (which aspirate material from above the cuff space), patient positioning, mobilization, humidification, changes in ventilation, sputum management (physiotherapy, suction, medical treatment) or the use of anticholinergic medications. ${ }^{30}$ Evaluation of ability to manage oral secretions is a frequent intervention for SLT with therapeutic swallowing exercises often aimed at increasing patient awareness and clearance of saliva. Bedside clinical assessment of swallowing can be augmented by instrumental assessment, including videofluoroscopy and fiberoptic endoscopic evaluation of swallow (FEES). These specialist assessments can quantify secretion management, swallow safety and aspiration risk in tracheostomized patients and influence decannulation decisions. Bedside FEES performed by SLT is ideal for tracheostomized patients in ICU and is essential for detecting silent aspiration. FEES is a safe assessment for those presenting with high aspiration risks. It can also detect occult laryngeal injury, which may impact on airway patency or airway protection capability, contributing to MDT tracheostomy weaning decisions.

Ventilated patients or those unable to tolerate cuff deflation can still be assessed using FEES facilitating earlier recognition of dysphagia that may have a potentially detrimental impact on respiratory function and weaning. Head and neck surgical patients and those with underlying neurological diseases are at higher risk of aspiration, and the effects of mechanical ventilation, dysphagia and tracheostomy are associated with increased risk of pneumonia, length of stay, morbidity and mortality. ${ }^{30,61}$ Although occult aspiration rates may be as high as $60 \%$, some patients will be able to commence safe oral intake following FEES that simple clinical assessment would not have predicted. ${ }^{60,62-64}$ FEES also facilitates targeted rehabilitation of swallowing early on with implementation of individualized exercise programs and can more accurately predict the prognosis for recovery of swallow function. This is of particular importance for patients such as those with critical illness polyneuromyopathy who have a reported incidence of significant protracted dysphagia of $91 \% .{ }^{65}$ FEES enables SLTs to adopt a proactive, individualized approach without deferring swallowing assessment until cuff deflation expediting feeding decisions and rehabilitation. ${ }^{30}$ SLTs can also provide much-needed support to tracheostomized patients to minimize the negative impact of communication and swallowing difficulties within the MDT. 


\section{Specialist nursing staff}

Historical roles of specialist tracheostomy nursing staff have centered on head and neck surgical patients, but there has been recognition that these core skills are applicable and translatable to nonsurgical tracheostomy patients for some years. ${ }^{66}$ The first reports of specialist nursing teams managing increasing numbers of patients on nonsurgical wards described Critical Care "Outreach" teams which comprised mostly ICU nursing staff. ${ }^{67,68}$ Such teams were managing the transition from intensive nursing environments into more general ward care and were often called upon to educate ward staff around tracheostomy care. It has been widely recognized that nurses working outside of critical care or head and neck surgical environments can lack the experience, knowledge and confidence to provide safe and effective tracheostomy care. ${ }^{69}$

So whilst the hospital-wide specialist nursing roles may have had origins in education, with increasing numbers of non-head and neck surgical patients with tracheostomies in our hospitals, the role of specialist tracheostomy nurse is evolving. The support of a specialist tracheostomy nurse has been shown to decrease complication rates and, by supporting other nurses in more general ward environments, reduce readmissions to the ICUs, and even have an impact on overall length of stay. ${ }^{68}$

As with the other multidisciplinary positions, there are clear overlaps with other roles. This however is an advantage to the wider team, and specialist nursing roles can develop without impacting on learning opportunities or exposure for those working in other disciplines. ${ }^{70}$ Indeed, specialist nurse-led clinics may actually enhance opportunities for other health care professionals and medical staff to learn the best practice for management of the tracheostomy patients. ${ }^{70}$ Specialist nursing programs have been shown to be a costeffective method of improving hospital-wide tracheostomy care, even when overlapping with other roles from the MDT. ${ }^{68}$

\section{Other allied health care professionals}

The addition of a dietician into the tracheostomy MDT has been shown to be of benefit. ${ }^{21}$ Dieticians are not only expert in the amount and constituents of nutritional intake, but the best route of delivery. This can be difficult to predict and requires discussion with medical and surgical colleagues and SLTs in order to gauge likely recovery times from the current condition and safest and most effective routes for nutrition. Routes of administration may include intravenous means, percutaneous endoscopic gastrostomy or nasogastric/ nasojejunal routes, as well as oral intake.
Many patients who require tracheostomy present with, or are subsequently found to have, swallowing difficulties. This may mean that a degree of malnutrition is present which requires careful assessment and management by the dietetic team..$^{71,72}$

Occupational therapists may also have a role to play in improving functional performance or satisfaction with current performance, and whilst there is likely overlap with the management of related chronic conditions, this area remains largely unstudied for specific populations of tracheostomy patients. $^{73}$

Finally, there are many roles for the MDT to play in safely transitioning the care of an adult or child from the hospital to the community. These roles are often not well established, but there are reports of successful programs that educate staff, patients, parents and carers in the safe management of a tracheostomy, and there may be a reduction in hospital (re) admission following the implementation of such packages.

\section{Medical staff}

Medical staff have a key role in planning, performing and managing patient care at key points in their tracheostomy journey. Whilst medical staff have historically taken a leadership role in day-to-day patient management, there are published examples of successful tracheostomy MDTs that adopt a non-medical leadership model. ${ }^{19}$ The skills of experienced and highly trained medical and surgical staff remain essential, but with the increasing complexity of patients and the investigation and treatment options available, the expanded role of other members of the MDT must be welcomed. There are clear benefits in developing multispecialty care models for complex patients with tracheostomies, and engagement of medical and surgical teams within each other's historical practice has been described, with positive effects. ${ }^{74}$ Medical staff often retain overall responsibility and accountability for patient care, and so local agreement about the roles of MDT care and management must be agreed.

\section{Psychologists}

Critical illness is known to cause delirium and may lead to posttraumatic stress disorders. In addition, the inability to speak and communicate is a well-recognized cause of anxiety and can lead to reduced compliance with care and prolonged inpatient episodes. ${ }^{30,75}$ Altered body image can affect the well-being and psychological status of a tracheostomized patient, which may be influenced by offering professional, targeted psychological support. ${ }^{76}$ It is likely that a combined approach from SLTs and psychologists will address some of 
the psychological consequences of tracheostomy, although research in this area is currently limited.

\section{Family and friends}

Whilst not strictly part of the MDT, support from friends and families can be as important as professional care. Supportive family members may become primary carers, especially if the patient is discharged into the community with a tracheostomy. Successful, integrated predischarge tracheostomy education programs have been described for pediatric patients, comprising hands-on training, emergency management training, resources and support links from the hospital. ${ }^{77-79}$ One survey of such carers found that less than half of respondents felt adequately prepared at the time of discharge, highlighting future challenges for the tracheostomy MDT. ${ }^{80}$

\section{Coordinating the MDT}

Thus far, we have highlighted the roles of individuals within the multidisciplinary tracheostomy team and the skills that these team members can offer. However, there is increasing evidence of the collective effectiveness of this team approach to tracheostomy care.

MDTs have been shown to be effective throughout the patient journey, from patient selection and counseling around insertion of the tracheostomy, within the ICU to reduce weaning time and weaning failure, through to ward-based educational programs to improve patient safety and reduce complications and readmissions. ${ }^{21,81-84}$ Better coordination of care can improve the efficiency of the interdisciplinary team and ensure appropriate therapies, and interventions are considered and actioned in a timely manner and contribute to reductions in length of stay. ${ }^{81,85,86}$ There are likely to be significant cost benefits if these outcomes are consistently replicated. ${ }^{19,83,87}$ Anecdotally, simply having discussions between different health care professionals around the benefits of specific interventions can be enlightening. For example, the role of drying agents for oral secretions, perhaps with cuff deflation and weaning from ventilatory support as a goal, can have a negative impact on respiratory secretion management and risk of respiratory complications. Expertise from each discipline is needed to have a fully informed decision, ideally involving the patients and their family if possible. ${ }^{78}$

\section{Conclusion}

Multidisciplinary care is expanding in order to manage the complex needs and expectations of tracheostomy patients. Individually and collectively, multidisciplinary health care professionals can have a significant impact on care for individual patients, nonspecialist teams and our wider institutions and communities. The impact of multidisciplinary care has been judged largely by cohort comparisons care from a dedicated MDT versus standard or historical care, using end points such as reductions in time to decannulation, length of stay and adverse events. ${ }^{88}$ These metrics probably reflect better coordination and more effective care, but the impacts on quality of care are not generally reported. Initiatives such as the Global Tracheostomy (Quality Improvement) Collaborative (www.globaltrach.org) have the potential to collect meaningful patient-level data around the quality of care delivered. ${ }^{89}$ Quality improvement programs such as this can deliver data that are relevant to patients and their families, multidisciplinary health care professionals and also hospital administrators that can comprehensively benchmark the effectiveness of multidisciplinary tracheostomy care in the future.

\section{Acknowledgment}

This paper was supported by the Health Foundation.

\section{Disclosure}

Dr McGrath is chair of the UK National Tracheostomy Safety Project and European Lead of the Global Tracheostomy Collaborative. The other authors report no conflicts of interest in this work.

\section{References}

1. NHS. Hospital Episode Statistics. 2013. Available from: http://www. hesonline.nhs.uk/Ease/servlet/ContentServer?siteID=1937. Accessed February 26, 2017.

2. McGrath BA, Ramsaran R, Columb MO. Estimating the number of tracheostomies performed in critical care in England. Br J Anaesth. 2012;109(4):662P.

3. Martin IC, Freeth H, Kelly K, Mason M. NCEPOD: on the right trach? 2014. Available from: www.ncepod.org.uk/2014tc.html. Accessed October 20, 2016

4. Young D, Harrison DA, Cuthbertson BH, Rowan K; TracMan Collaborators. Effect of early vs late tracheostomy placement on survival in patients receiving mechanical ventilation. JAMA. 2013;309(20): 2121-2129.

5. Fischler L, Erhart S, Kleger GR, Frutiger A. Prevalence of tracheostomy in ICU patients. A nation-wide survey in Switzerland. Intensive Care Med. 2000;26(10):1428-1433.

6. Blot F, Melot C; Commission d'Epidémiologie et de Recherche Clinique. Indications, timing, and techniques of tracheostomy in 152 French ICUs. Chest. 2005;127(4):1347-1352.

7. Vincent JL, Suter P, Bihari D, Bruining H. Organization of intensive care units in Europe: lessons from the EPIC study. Intensive Care Med. 1997;23(11):1181-1184.

8. Freeman BD, Borecki IB, Coopersmith CM, Buchman TG. Relationship between tracheostomy timing and duration of mechanical ventilation in critically ill patients. Crit Care Med. 2005;33(11):2513-2520.

9. Cheung NH, Napolitano LM. Tracheostomy: epidemiology, indications, timing, technique, and outcomes. Respir Care. 2014;59(6):895-919.

10. Yu M. Tracheostomy patients on the ward: multiple benefits from a multidisciplinary team? Crit Care. 2010;14(1):109-112. 
11. McGrath BA, Wilkinson K. The NCEPOD study: on the right trach? Lessons for the anaesthetist. Br J Anaesth. 2015;115(2):155-158.

12. McComb S, Hebdon M. Enhancing patient outcomes in healthcare systems through multidisciplinary teamwork. Clin J Oncol Nurs. 2013;17(6):669-672.

13. van Hoof J, Zwerts-Verhelst EL, Nieboer ME, Wouters EJ. Innovations in multidisciplinary education in healthcare and technology. Perspect Med Educ. 2015;4(3):146-148.

14. Rumbak MJ, Newton M, Truncale T, Schwartz SW, Adams JW, Hazard PB. A prospective, randomized, study comparing early percutaneous dilational tracheotomy to prolonged translaryngeal intubation (delayed tracheotomy) in critically ill medical patients. Crit Care Med. 2004;32(8):1689-1694.

15. Reibel JF. Decannulation: how and where. Respir Care. 1999;44:856-860.

16. Harkin H. Tracheostomy management. Nurs Times. 1998;94(21):56-58.

17. Ladyshewsky A, Gousseau A. Successful tracheal weaning. Can Nurse. 1996;92(2):35-38.

18. Gilbert RW, Bryce DP, Mcllwain JC, Ross IR. Management of patients with long-term tracheostomies and aspiration. Ann Otol Rhinol Laryngol. 1987;96(5):561-564.

19. Cameron TS, McKinstry A, Burt SK, et al. Outcomes of patients with spinal cord injury before and after introduction of an interdisciplinary tracheostomy team. Crit Care Resusc. 2009;11(1):14-19.

20. Hunt K, McGowan S. Tracheostomy management in the neurosciences: a systematic, multidisciplinary approach. Br J Neurosci Nurs. 2005;1(3):122-125.

21. Cetto R, Arora A, Hettige R, et al. Improving tracheostomy care: a prospective study of the multidisciplinary approach. Clin Otolaryngol. 2011;36(5):482-488.

22. McGrath BA, Doherty C. Quality of tracheostomy care is probably as important as timing. Br J Anaesth. 2016;116(2):300.

23. Thomas AN, McGrath BA. Patient safety incidents associated with airway devices in critical care: a review of reports to the UK National Patient Safety Agency. Anaesthesia. 2009;64(4):358-365.

24. Cook TM, Woodall N, Frerk C; on behalf of the Fourth National Audit Project. Major complications of airway management in the UK: results of the Fourth National Audit Project of the Royal College of Anaesthetists and the Difficult Airway Society. Part 1: anaesthesia. Br JAnaesth 2011;106(5):617-631.

25. Halum SL, Ting JY, Plowman EK, et al. A multi-institutional analysis of tracheotomy complications. Laryngoscope. 2012;122(1):38-45.

26. Mortimer H, Kubba H. A retrospective case series of 318 tracheostomyrelated adverse events over 6 years - a Scottish context. Clin Otolaryngol. 2017;42(4):936-940.

27. Templeton R, Webster K, McGrath BA. Patient safety incidents associated with displaced or obstructed tracheostomies: comparison of levels of harm between critical care and ward environments. $\mathrm{Br} J$ Anaesth. 2011;107(5):834-835.

28. McGrath BA, Thomas AN. Patient safety incidents associated with tracheostomies occurring in hospital wards: a review of reports to the UK National Patient Safety Agency. Postgrad Med J. 2010;86(1019):522-525.

29. McGrath BA, Wilkinson K, Shah RK. Notes from a Small Island: lessons from the UK NCEPOD Tracheotomy Report. Otolaryngol Head Neck Surg. 2015;153(2):167-169.

30. McGrath BA, Wallace S. The UK National Tracheostomy Safety Project and the role of speech and language therapists. Curr Opin Otolaryngol Head Neck Surg. 2014;22(3):181-187.

31. Hettige R, Arora A, Roberson DW, Narula AA. Recent developments to improve the standards of tracheostomy care. $\mathrm{Br} J$ Intensive Care. 2013;(Autumn):89-92.

32. Gosselink R, Bott J, Johnson M, et al. Physiotherapy for adult patients with critical illness: recommendations of the European Respiratory Society and European Society of Intensive Care Medicine Task Force on Physiotherapy for Critically Ill Patients. Intensive Care Med. 2008;34(7):1188-1199.

33. Macmahon C. Breathing and physical exercises for use in cases of wounds in the pleura, lung and diaphragm. Lancet. 1915;186(4805):769-770.
34. Bott J, Blumenthal S, Buxton M, et al; British Thoracic Society Physiotherapy Guideline Development Group. Guidelines for the physiotherapy management of the adult, medical, spontaneously breathing patient. Thorax. 2009;64(Suppl 1):i1-i51.

35. Sheehan RL, Niven RM, Ryan DM. Comparison of safety and efficacy of airway clearance techniques, hypertonic saline and bronchoscopy in a severe asthma service. Thorax. 2016;71(Suppl 3):A152-A153.

36. Denehy L. The use of manual hyperinflation in airway clearance. Eur Respir J. 1999;14(4):958-965.

37. Pathmanathan N, Beaumont N, Gratrix A. Respiratory physiotherapy in the critical care unit. Contin Educ Anaesth Crit Care Pain. 2015;15(1):20-25.

38. Sorenson HM, Shelledy DC; AARC. AARC clinical practice guideline. Intermittent positive pressure breathing -2003 revision \& update. Respir Care. 2003;48(5):540-546.

39. Kalanuria AA, Ziai W, Mirski M. Ventilator-associated pneumonia in the ICU. Crit Care. 2014;18(2):208

40. Ntoumenopoulos G, Presneill JJ, McElholum M, Cade JF. Chest physiotherapy for the prevention of ventilator-associated pneumonia. Intensive Care Med. 2002;28(7):850-856.

41. Kahn JM, Benson NM, Appleby D, Carson SS, Iwashyna TJ. Longterm acute care hospital utilization after critical illness. JAMA. 2010;303(22):2253-2259.

42. National Institute for Health and Clinical Excellence. NICE CG 83: rehabilitation after critical illness in adults. 2009. Available from: https:// www.nice.org.uk/guidance/cg83/resources/rehabilitation-after-criticalillness-in-adults-975687209413. Accessed February 10, 2017.

43. Ambrosino N, Venturelli E, Vagheggini G, Clini E. Rehabilitation, weaning and physical therapy strategies in chronic critically ill patients. Eur Respir J. 2012;39(2):487-492.

44. Corner EJ, Soni N, Handy JM, Brett SJ. Construct validity of the Chelsea critical care physical assessment tool: an observational study of recovery from critical illness. Crit Care. 2014;18(2):R55.

45. Skinner EH, Berney S, Warrillow S, Denehy L. Development of a physical function outcome measure (PFIT) and a pilot exercise training protocol for use in intensive care. Crit Care Resusc. 2009;11(2):110-115.

46. Burtin C, Clerckx B, Robbeets C, et al. Early exercise in critically ill patients enhances short-term functional recovery. Crit Care Med. 2009;37(9):2499-2505.

47. Pohlman MC, Schweickert WD, Pohlman AS, et al. Feasibility of physical and occupational therapy beginning from initiation of mechanical ventilation. Crit Care Med. 2010;38(11):2089-2094.

48. Fitzgerald C, Brown C, Main E. Peak cough flow via tracheostomy - a useful assessment tool before decannulation? JAssoc Chart Physiother Respir Care. 2013;45:43.

49. Santus P, Gramegna A, Radovanovic D, et al. A systematic review on tracheostomy decannulation: a proposal of a quantitative semiquantitative clinical score. BMC Pulm Med. 2014;14(1):201.

50. McGrath BA. Comprehensive Tracheostomy Care: The National Tracheostomy Safety Project Manual. 1st ed. McGrath BA, editor. Wiley; 2014. Bognor Regis, UK.

51. Royal College of Speech and Language Therapists. Position paper: speech and language therapy in adult critical care. 2014. Available from: https://www.rcslt.org/members/publications/publications2/criticalcare_positionpaper_060114. Accessed February 10, 2017.

52. Thomas LA, Rodriguez CS. Prevalence of sudden speechlessness in critical care units. Clin Nurs Res. 2011;20(4):439-447.

53. McGrath BA, Lynch J, Wilson M, Nicholson L, Wallace S. Above cuff vocalisation: a novel technique for communication in the ventilatordependent tracheostomy patient. J Intensive Care Soc. 2015;17(1):19-26.

54. Sutt AL, Fraser JF. Speaking valves as part of standard care with tracheostomized mechanically ventilated patients in intensive care unit. $J$ Crit Care. 2015;30(5):1119-1120.

55. Sutt AL, Cornwell P, Mullany D, Kinneally T, Fraser JF. The use of tracheostomy speaking valves in mechanically ventilated patients results in improved communication and does not prolong ventilation time in cardiothoracic intensive care unit patients. J Crit Care. 2015;30(3):491-494. 
56. Engels PT, Bagshaw SM, Meier M, Brindley PG. Tracheostomy: from insertion to decannulation. Can J Surg. 2009;52(5):427-433.

57. Speed L, Harding KE. Tracheostomy teams reduce total tracheostomy time and increase speaking valve use: a systematic review and metaanalysis. J Crit Care. 2013;28(2):216.e1-216.e10.

58. Leder SB, Ross DA. Incidence of vocal fold immobility in patients with dysphagia. Dysphagia. 2005;20(2):163-167.

59. Intensive Care Society. GPICS: Guidelines for the provision of intensive care services. 2015. Available from: https://www.ics.ac.uk/ICS/ guidelines-and-standards.aspx. Accessed July 23, 2016.

60. Kang JY, Choi KH, Yun GJ, Kim MY, Ryu JS. Does removal of tracheostomy affect dysphagia? A kinematic analysis. Dysphagia. 2012;27(4):498-503.

61. Alsumrain M, Melillo N, Debari VA, et al. Predictors and outcomes of pneumonia in patients with spontaneous intracerebral hemorrhage. $J$ Intensive Care Med. 2013;28(2):118-123.

62. McGowan SL, Gleeson M, Smith M, Hirsch N, Shuldham CM. A pilot study of fibreoptic endoscopic evaluation of swallowing in patients with cuffed tracheostomies in neurological intensive care. Neurocrit Care. 2007;6(2):90-93.

63. Wallace S, Wilson M. Occult laryngeal pathology detected by FEES (abstract and poster). London: Intensive Care Society, State of the Art; 2013.

64. Hales PA, Drinnan MJ, Wilson JA. The added value of fibreoptic endoscopic evaluation of swallowing in tracheostomy weaning. Clin Otolaryngol. 2008;33(4):319-324.

65. Ponfick M, Linden R, Nowak DA. Dysphagia - a common, transient symptom in critical illness polyneuropathy: a fiberoptic endoscopic evaluation of swallowing study. Crit Care Med. 2015;43(2):365-372.

66. Russell C, Harkin $\mathrm{H}$. The benefits of tracheostomy specialist nurses. Nurs Times. 2001;97(46):40-41.

67. Lewis T, Oliver G. Improving tracheostomy care for ward patients. Nurs Stand. 2005;19(19):33-37.

68. Sodhi K, Shrivastava A, Singla MK. Implications of dedicated tracheostomy care nurse program on outcomes. J Anesth. 2014;28(3):374-380.

69. Paul F. Tracheostomy care and management in general wards and community settings: literature review. Nurs Crit Care. 2010;15(2):76-85.

70. Crosbie R, Cairney J, Calder N. The tracheostomy clinical nurse specialist: an essential member of the multidisciplinary team. J Laryngol Otol. 2014;128(2):171-173.

71. Talwar B, Donnelly R, Skelly R, Donaldson M. Nutritional management in head and neck cancer: United Kingdom National Multidisciplinary Guidelines. J Laryngol Otol. 2016;130(S2):S32-S40.

72. Wong S, Derry F, Jamous A, Hirani SP, Forbes A. Is undernutrition risk associated with an adverse clinical outcome in spinal cord-injured patients admitted to a spinal centre? Eur J Clin Nutr. 2014;68(1): 125-130.

73. Martinsen U, Bentzen H, Holter MK, et al. The effect of occupational therapy in patients with chronic obstructive pulmonary disease: a randomized controlled trial. Scand J Occup Ther. 2017;24(2):89-97.
74. Rubin AD, Griffin GR, Hogikyan ND, Feldman EL. A new member of the multidisciplinary ALS team: the otolaryngologist. Amyotroph Lateral Scler. 2012;13(2):229-232.

75. Breckenridge SJ, Chlan L, Savik K. Impact of tracheostomy placement on anxiety in mechanically ventilated adult ICU patients. Heart Lung. 2014;43(5):392-398.

76. Gilony D, Gilboa D, Blumstein T, et al. Effects of tracheostomy on well-being and body-image perceptions. Otolaryngol Head Neck Surg. 2005;133(3):366-371.

77. Joseph RA. Tracheostomy in infants: parent education for home care. Neonatal Netw. 2011;30(4):231-242.

78. McCormick ME, Ward E, Roberson DW, Shah RK, Stachler RJ, Brenner MJ. Life after tracheostomy: patient and family perspectives on teaching, transitions, and multidisciplinary teams. Otolaryngol Head Neck Surg. 2015;153(6):914-920.

79. McGowin K. Decreasing emergency department visits and hospital admission in the pediatric tracheostomy population. ORL Head Neck Nurs. 2015;33(3):6-9.

80. Szondy MV, Morton DE, Parrott HM, Bazzy-Asaad A, Tolomeo CT. Standardizing family education in a pediatric respiratory care unit. $J$ Pediatr Nurs. 2014;29(3):272-278.

81. Berney L, Wasserfallen JB, Grant K, et al. Acute neurorehabilitation: does a neurosensory and coordinated interdisciplinary programme reduce tracheostomy weaning time and weaning failure? NeuroRehabilitation. 2014;34(4):809-817.

82. Parker V, Shylan G, Archer W, McMullen P, Morrison J, Austin N. Trends and challenges in the management of tracheostomy in older people: the need for a multidisciplinary team approach. Contemp Nurse. 2007;26(2):177-183.

83. Mirski MA, Pandian V, Bhatti N, et al. Safety, efficiency, and costeffectiveness of a multidisciplinary percutaneous tracheostomy program. Crit Care Med. 2012;40(6):1827-1834.

84. McGrath BA, Calder N, Laha S, et al. Reduction in harm from tracheostomy-related patient safety incidents following introduction of the National Tracheostomy Safety Project: our experience from two hundred and eighty-seven incidents. Clin Otolaryngol. 2013;38(6):541-545.

85. de Mestral C, Iqbal S, Fong N, et al. Impact of a specialized multidisciplinary tracheostomy team on tracheostomy care in critically ill patients. Can J Surg. 2011;54(3):167-172.

86. Pandian V, Miller CR, Schiavi AJ, et al. Utilization of a standardized tracheostomy capping and decannulation protocol to improve patient safety. Laryngoscope. 2014;124(8):1794-1800.

87. Pandian V, Miller CR, Mirski MA, et al. Multidisciplinary team approach in the management of tracheostomy patients. Otolaryngol Head Neck Surg. 2012;147(4):684-691.

88. Garrubba M, Turner T, Grieveson C. Multidisciplinary care for tracheostomy patients: a systematic review. Crit Care. 2009;13(6):R177.

89. McGrath BA, Lynch J, Bonvento B, et al. Evaluating the quality improvement impact of the Global Tracheostomy Collaborative in four diverse NHS hospitals. BMJ Qual Improv Rep. 2017;6(1):u220636.w7996.
Journal of Multidisciplinary Healthcare

\section{Publish your work in this journal}

The Journal of Multidisciplinary Healthcare is an international, peerreviewed open-access journal that aims to represent and publish research in healthcare areas delivered by practitioners of different disciplines. This includes studies and reviews conducted by multidisciplinary teams as well as research which evaluates the results or conduct of such teams or health

\section{Dovepress}

care processes in general. The journal covers a very wide range of areas and welcomes submissions from practitioners at all levels, from all over the world. The manuscript management system is completely online and includes a very quick and fair peer-review system. Visit http://www.dovepress.com/ testimonials.php to read real quotes from published authors. 